\title{
Crack Treatment of Sprayed Concrete Layer in Tail Water Surge Chamber of Guandi Hydropower Station During Operation
}

\section{Yun Zhang}

Yalong River Hydropower Development Co., Ltd., China

\begin{abstract}
The dimensions of the tail water surge chamber of Guandi Hydropower Station are $205 \mathrm{~m} \times 21.5 \mathrm{~m} \times 57$ (length $\times$ width $\times$ height), and the top $21.5 \mathrm{~m}$ area is permanently lined with net-jet concrete. Sprayed concrete cracking occurred during the excavation construction process, and cracking, peeling, and block dropping occurred again after the power station was in operation. According to geological conditions, field surveys, and monitoring instrument data analysis, it is believed that the surrounding rock is stable overall, and the cracks are mainly manifested by shallow surface relaxation caused by stress release in the shallow surface rock mass of the tailing chamber and cracking failure of the concrete spray layer. The cracked and damaged sprayed concrete cracking was treated while the power station remained in operation. Processing was completed in November 2015 and the power station is currently running well.
\end{abstract}

Keywords: underground cavern; sprayed concrete cracking; treatment during operation

\section{Project Overview}

Guandi Hydropower Station is located in Daluo Village, at the junction of Xichang City and Yanyuan County, Liangshan Yi Autonomous Prefecture, Sichuan Province. It is the third cascade hydropower planning five-stage development method for the Kara-Jianghekou section of the Yalong River. The main task of the power station is to generate electricity. The normal water storage level of the reservoir is $1330.00 \mathrm{~m}$, with a total storage capacity of 760 million $\mathrm{m}^{3}$. The underground powerhouse on the right bank is equipped with four $(4 \times 600 \mathrm{MW})$ hydro-generator units. The average annual power generation for many years is 11.767 billion $\mathrm{kW} \cdot \mathrm{h}$. The construction of the Guandi Hydropower Station started in October 2004. In March 2013, all four units were put into production.

The centerline of the tail water surge chamber is located on the $0+144.25$ pile in the longitudinal direction of the plant, and is arranged parallel to the main transformer room. The distance from the centerline of the main transformer room is $68.95 \mathrm{~m}$, and it forms an underground cave group with other caves. The size of the tail water surge chamber is $205 \mathrm{~m} \times$ $21.5 \mathrm{~m} \times 57 \mathrm{~m}$ (length $\times$ width $\times$ height), and a $17 \mathrm{~m}$ thick rock pillar partition wall is set in between. Below the top of the partition wall is $1229.50 \mathrm{~m}$, the surge tank is divided into two rooms. The maximum vertical burial depth is about $227 \mathrm{~m}$, the excavation floor elevation is $1193.00 \mathrm{~m}$, and the top arch elevation is $1251.00 \mathrm{~m}$. The concrete lining is around $1229.50 \mathrm{~m}$ of the surge chamber, and the side walls and top arches are supported by anchor sprayed concrete: the sprayed concrete is dry spray C25 concrete, the top arch thickness is $20 \mathrm{~cm}$, the side wall thickness is $15 \mathrm{~cm}$, and the end wall thickness is $15 \mathrm{~cm}$. 
The elevation of the maintenance platform of the surge tank is $1218.50 \mathrm{~m}$, and the elevation of the working platform is $1241.50 \mathrm{~m}$

\section{Cracking and Analysis of Concrete Spraying Layer in Tail Chamber}

\subsection{Cracking}

During the excavation of the tail water surge chamber, three obvious cracks in the sprayed concrete appeared in the top arch in July, October, and November $2008^{[1]}$, and then the geophysical survey was supplemented and combined with monitoring data and geological conditions, the stability of the cavern was analyzed during construction. It is believed that the cracks were affected by various factors such as construction blasting, geological structural planes, and the adjustment of the surrounding rock's own stress and deformation. Local strengthening support was carried out during the construction process.

After the operation of the power station, a site survey of the tail-adjusting chamber in May 2014 found the cracks, peeling, and falling of the arch sprayed concrete on the side of the tail-adjusting chamber. The cracks are generally several millimeters wide, four to five $\mathrm{cm}$ in some cases, and the length of the cracks is tens of centimeters to several meters. There are localized blocks, and the size of the fan diagram is several centimeters to tens of centimeters. It is mainly divided into three areas, including two top arches (numbered cracked areas two, three), and one upstream side wall (numbered cracked area one). The area of cracked area one is about $600 \mathrm{~m}^{2}$, the area of cracked area two is about $700 \mathrm{~m}^{2}$, and the area of cracked area three is about $450 \mathrm{~m}^{2}$. The cracking phenomenon develops in the sprayed concrete layer, generally not deep to the rock, and there is a phenomenon of void between the sprayed concrete layer and the rock mass, showing obvious tensile characteristics.

\subsection{Cause analysis}

The maximum measured first principal stress of Guandi underground plant is $35 \mathrm{MPa}$, which belongs to high in-situ stress. The surrounding rock mass of the cavern in the underground plant area is basalt. The rock has high compressive strength and good energy storage conditions. Slow-inclined angle cracks develop near the side roof arch. After the excavation of the surrounding rock in the cave, there is a process of stress adjusting, due to the high geo stress and high compressive strength of the surrounding rock, this process will last for a long time.

According to the cracking of the sprayed layer seen from the field survey, the thickness of the sprayed layer in the cracks of the steel fiber concrete sprayed layer is significantly smaller than the designed sprayed layer thickness, which reduces the support strength of the sprayed layer and cannot adapt to the stress release. This caused the formation of empty shells and delaminating between the sprayed concrete layer and the rock mass.

\subsection{Understanding of surrounding rock stability}

According to the investigation, the data of the multi-point displacement gauge, anchor stress gauge, anchor cable dynamometer, and seam gauge of each monitoring section of the tail adjustment room have not changed abnormally for a long period. According to comprehensive research, the surrounding rock of the tail chamber is generally stable. The cracks appearing in the side arch are mainly manifested by the shallow surface relaxation caused by the stress release of the shallow surface rock mass in the tail chamber and the cracking failure of the concrete spray layer.

\section{Treatment Measures}

For the treatment of damaged sprayed concrete, the construction scaffolding was first erected, and then the cracked and voided part of the original sprayed mixed layer of the side arch was removed, and then the original sprayed concrete and steel mesh were restored as required. Processing was completed in November 2015 and is currently running well. 


\subsection{Construction scaffolding}

The tailgate room (except the installation room) is distributed on the hoisting machine platform EL1241.5. The hoisting machine track beam is composed of two $4 \mathrm{~m}$ spaced-apart column columns. The height of the frame columns is EL1218.5 to EL1241.5, the others are tail chamber cavity, two headstock track beams are distributed on the upstream side of the tailgate chamber, one is close to the upstream side wall of the tailgate chamber, the width is $2 \mathrm{~m}$, and the total width of the lifting space and the other track beam is $9.35 \mathrm{~m}$. A $6.5 \mathrm{~m} \times 12 \mathrm{~m}$ bridge crane is arranged on the track beam. The width of the upstream edge of the bridge platform from the upstream side wall of the tail room is about $1 \mathrm{~m}$. According to the actual site conditions of the above site construction, it was decided to select the bridge crane arranged on the hoisting platform of the tailgate as the construction platform for the construction scaffolding, and move the construction scaffolding to the corresponding working surface by operating the bridge crane. Construction erection shall not affect the main structure and function of the bridge crane. The working platform adopts the method of "wood board and fireproof tarpaulin" to do a good job of bridge crane safety protection, to avoid the damage caused by falling of concrete blocks, sprayed concrete rebound, and pollution of bridge crane equipment.

\subsection{Gouge out the cracked and empty part}

Ensure that the original spray mixed layer is cracked, hollowed out and cleaned in place, cut deep to the bedrock surface, and cut horizontally more than $20 \mathrm{~cm}$ beyond the voided boundary. When gouging, the electric block should be gradually broken and separated. It is strictly forbidden to use a crowbar to prune the whole part of the evacuation part, so as to prevent the massive block from falling off, causing damage to the rack and personnel. At the same time, make sure that it is completely removed and cleaned. The gouge blocks are collected and transported to the slag yard.

\subsection{Restoration of sprayed concrete support}

Check the spray surface before spraying to ensure that there is no residual pumice. Use a high-pressure water gun to flush the spray surface, and conduct a comprehensive inspection of the construction machinery and equipment, the wind and water pipelines. If it is found that the reinforcement mesh is missing in the original sprayed concrete structure layer, it is necessary to re-install the reinforcement mesh before carrying out the sprayed concrete construction. Select qualified materials and perform sprayed concrete restoration according to the original supporting concrete mix ratio. The sprayed concrete is layered and layered sequentially, the spraying order is from bottom to top, and the thickness of the sprayed layer is appropriate so that the sprayed layer does not drop and slip. After spraying the concrete, it shall be cured according to regulations.

\subsection{Acceptance and withdrawal}

During the process, check and evaluate according to the procedures, and finally accept. After the construction is completed, the construction scaffold is removed, and the welding points on the bridge are polished and painted to restore the normal operation of the bridge.

\section{Important Notes}

During the process, the power station is operating normally. Fluctuations in the water level in the surge tank during load shedding will cause changes in the pressure and wind speed in the surge tank and its traffic tunnel. Therefore, when construction workers are operating, avoid this period of time, or the central control room promptly informs to arrange the evacuation of construction workers.

Monitoring equipment is installed in the tail adjustment room, and the construction rack is installed on the bridge crane, which can not affect the normal function of the bridge crane and the main structure. The construction workers are facing the water at high altitude. During the process, not only to ensure the safety of the construction itself, but also to 
bridge and monitoring equipment for protection.

\section{References}

[1] Huang Kejian. (2017) Crack Analysis and Treatment of the Top Arch Spray Layer in the Tail Water Surge Chamber of Guandi Hydropower Station. Heilongjiang Hydraulic Engineering, 45 (6): 125-128.

[2] Jia Yan, Zhang Xiaohong, Diao Xuefen, Zhang Junfa, Zhan Xiaotao. (2017) Sensitivity Analysis of Cross Sectional Area of Tail Water Surge Tank of Hydropower Station. Journal of Water Resources and Water Engineering, 28 (06): 129-133.

[3] Bao Haiyan, Fu Liang, Yang Jiandong. (2014) Discussion on the Setting Conditions of the Tail Water Surge Chamber of Pumped Storage Hydropower station. Journal of Hydroelectric Engineering, 33 (01): 95-101. 